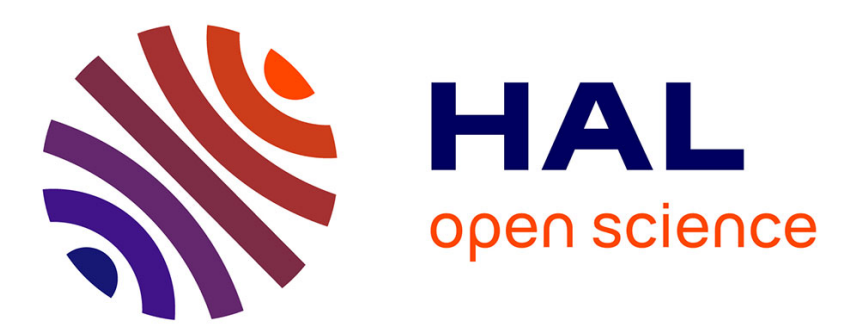

\title{
SOME BINAURAL FACTORS IN AUDITORY DEPTH ESTIMATION
}

R. Gatehouse, D. Worling, G. Caine

\section{To cite this version:}

R. Gatehouse, D. Worling, G. Caine. SOME BINAURAL FACTORS IN AUDITORY DEPTH ESTIMATION. Journal de Physique IV Proceedings, 1992, 02 (C1), pp.C1-265-C1-268. 10.1051/jp4:1992156 . jpa-00251227

\section{HAL Id: jpa-00251227 https://hal.science/jpa-00251227}

Submitted on 1 Jan 1992

HAL is a multi-disciplinary open access archive for the deposit and dissemination of scientific research documents, whether they are published or not. The documents may come from teaching and research institutions in France or abroad, or from public or private research centers.
L'archive ouverte pluridisciplinaire HAL, est destinée au dépôt et à la diffusion de documents scientifiques de niveau recherche, publiés ou non, émanant des établissements d'enseignement et de recherche français ou étrangers, des laboratoires publics ou privés. 
JOURNAL DE PHYSIQUE IV

Colloque C1, supplément au Journal de Physique III, Volume 2, avril 1992

C1-265

\title{
SOME BINAURAL FACTORS IN AUDITORY DEPTH ESTIMATION
}

\author{
R.W. GATEHOUSE, D. WORLING and G.D. CAINE \\ Department of Psychology, University of Guelph, Guelph, Ontario N1G 2W1, Canada
}

\section{ABSTRACT}

Two studies using the Gatehouse (1983) paradigm for depth estimation were done. In study I, two "normals", 2 binaurally - and, 2 monaurally - impaired hearers attempted to align 1.0 or $4.0 \mathrm{kHz}$ comparison (Co) tones with a $2.0 \mathrm{kHz}$ fixed position standard (std). Subjects with binuaral hearing-impairments were not much poorer at accurately estimating depth than were monaural or "normal" hearers. The most salient cue to accuracy seemed to be the initial distance (IP; indicative of signal intensities) that the Co was set away from the observer, and from the std's position, rather than the signals' frequency content. In study II, nine "normal" hearers did the task with gignals respectively that were WN as Co and a $1.0 \mathrm{KHz}$ tone as std, or vice verga. The total co to std. distances involved were reduced to $2 \mathrm{~m}$. Ss did the task under three conditions: 1) usual sagittal plane entry; or oriented so that signals entry was to their, 2) right (R90) or 3) left ears (L90). Results showed that accuracy under sagittal entry, where presumably binaural cues are minimized, was as good as with left or right ear entries. Unlike our earlier studies, intensity was not (unequivocally) the major cue involved because interactions were observed with both co content and movement directions. Perhaps WN takes on masking roles with effects that differ as signals are moved closer together.

\section{SOMMAIRE}

Deux expériences fondées sur la méthode de Gatehouse (1983) permettant une reconnaisance la gravité de son ont été realisées. Dans numéro uN, deux sujets "normaux', deux déficients unilatéraux, et deux deficients auditifs bilatéraux, essayèrent de mettre à niveau 1.0 ou $4.0 \mathrm{kHz}$ une ton comparison (Co) avec une position standard (std) fixee de 2.0kHz. En ce qui concerne l'exactitude dans l'estimation de la gravité, les deficients bilatéraux n'eurent pas beaucoup plus de difficultes que les autres sujets. Le factuer pertinent dans la précision semble être la distance intiale (i.e. IP, indicateur de l'intensité du son) Co était fixé loin des sujets et la position et de la standard, plutôt qu'en rapport avec la gamme des fréquences des sons. Dans numéro DEUX, neuf sujets "normaux" travaillérent sur des tons qui étaient respectivement wN pour co et $1.0 \mathrm{kHz}$ en std. ou vice-versa. Ces sujets accomplirent l'exercise dans trois conditions d'écoute suivantes: 1) entrée en plan sagittal; ou orientée 2) oreille droite (R90); 3) oreille gauche (L90). Les résultats montrérent que l'exactitude sous entrée sagittal ou les facteurg bilatéraux sont présumés reduits au minimum, était aussi bonne que sous les autres entrée orientée. Contrairement à nos précédents travaux, incontestablement, l'intensité n'a pas joue le rôle principal car on a observé des interactions significatives tant un plan du Co qu'an plan des directions des mouvements (positif ou négatif) effectués pour la mise a niveau des signaux. Le wN jouerait peut-etre le role de masque dont les effetg différeraient en fonction des mouvements de rapprochment des signaux entre eux. 
Since 1909 (Starch \& Crawford; Gamble), few papers have been published on acoustic depth perception, and most which have been done, have used classic scaling techniques. That is observers judged or estimated how far away from themselves (or from other arbitrary anchor points) statically positioned, and often, single sources were. There are a few instances of multiple and/ or moving sources estimates. No definitive explanations for depth judgement accuracy have emerged, but following conditions have been studied: interaural intensity cues as a function of distances (Coleman, 1963); spectral and/ or frequency content (Coleman,1968; Blauext, 1983); head movements (simpson \& Stanton,1973); median vs aural plane factors (Gardner,1969); proximity image effects (Mershon et. al.,1980); moving vs static signals (Waugh et.al.,1981); monaural impairment (Gatehouse \& Pattee, 1985). Mershon, with several co-authors $(1975 ; 1979$; 1980; 1989), has partially modeled the degree to which some of the above conditions contribute absolute (scalar) or relative (non scalar) information depth resolution.

Gatehouse (1983) introduced a depth estimation method which required seated blinfolded subjects to align, or "equate the depth of" an movable sagittal plane comparison (Co) with an alternately sounding fixed position standard (Std) signal. Co and Std signals varied in frequency, were equated in level (db SPL) at Std'B position, and were delivered at " 0 " degrees azimuth and elevation relative to a $\underline{s}^{\prime}$ height. Five Initial Positions (IP's) or placements of co prior to adjustment were tested $(+/-2 \mathrm{~m} ;+/-1 \mathrm{~m} ;$ and " $\mathrm{l})$. The "O" IP's were "catch" trials where no depth adjustment was necessary to align the sources. Positive $(+)$ positions required movement away from and $(-)$ required movement towards $\underline{s}$. At $+2 \mathrm{~m}$, for instance, Co's IP prior to adjustment was $1 \mathrm{~m}$ in front of $\underline{S}$, $2 \mathrm{~m}$ in front of std, and required movement "away from" him/her. Between trials, distance co was moved (cm) and error $(\mathrm{cm})$ from "true" alignment were recorded. ANOVA's and post hoc analyses were performed on: average movement, average errors collapsed across other conditions, and average ratio data. The latter measure overcomes bias imposed by the varied absolute Initial Positions of Co. Results (Gatehouse, 1983; Gatehouse \& Pattee, 1985) suggest intensity differences, as set up by varied IP's of Co from the static Std., were more salient depth cues than frequency differences. Generally however, it was easier to judge depth of lower frequency gignals. Movement direction also affects depth accuracy: "away from" results in over-, while movement "towards" observers causeg under-estimation of "true" signal depth.

The present studies were done to assess the possible roles of binaural inputs or cues in depth resolution.

\section{METHODS AND RESULTS}

Study I: Depth Judgements of Normal, Monaural, and Binaurally-Impaired Hearers Two subjects in each of 3 hearing conditions (HC; monaural; binaurallyimpaired; or binaurally "normal"), as audiometrically and clinically determined, aligned 1.0 or $4.0 \mathrm{kHz} C \mathrm{Co}^{\prime} \mathrm{s}$, with $2.0 \mathrm{kHz}$ std. signals. IP's were as in previous studieg. After five practice trials with alternating burgts from the 2.0 kHz std's "O" IP and either of the Co signals, 25 trials were presented i.e. five from each IP. Mixed factorial ANOVA's on 3 (HC) $x 2$ (Co frequency) $x$ (IP) were done. As in earlier studies, only an IP effect (i.e. intensity) was obtained for average movement and error data but not for ratio data. The latter analysis however, showed a HC xIP interaction $(F=8.14 ; p<.01)$. The HC factor was negated by post hoc tests clarifying the IP effects (see Fig.1). Other post hoc tests indicted that binaural and monaural hearers estimated depth about equally well. Binaurally impaired $s$ s though somewhat poorer at the task did move the co in the correct direction towards the std. Closer examination of directional effects ("0" trials removed), showed that all Sg, regardless of hearing status, underestimate depth in movements "away from self", and overestimate the std's depth with adjustments "towards self". The exception was the binaurally -impaired Sg at the -1.0 IP.

study II: Binaural Differences in Acoustic Depth Judgement

In previous studies to limit possible binaural cue differences, sg made 
adjustments facing the speakers along the sagittal plane (0 degrees orientation) However, since study I had shown no statistical differences between "normal" and impaired- hearer depth acuity, investigation whether "normal's" depth estimation accuracy was enhanced when such cues were more available was done.

Seven "normal" hearing undergraduates performed the task in two phases. In phase one, Co was a WN and the std a $1.0 \mathrm{kHz}$ tone. In phase two the Co and std signals were reversed. In each phase, SS made 15 depth judgments ( $3 \times 5$ IP' $s$ ) under three orientation conditions i.e.sagittal plane; $90 \mathrm{~L}$ (left ear facing speakers); $90 \mathrm{R}$ ( $r$ ight ear facing). Initial co positions were now spaced over 2 rather than $4 \mathrm{~m} .(i . e++/-1 \mathrm{~m}$; $+/-0.5 \mathrm{~m}$; "0"). The design was a within subjects repeated measures factorial: 3 (orientations) $\times 2$ (Co WN with std a tone; or the reverse) $\times 5$ (IP'g). For the first time using this paradigm, the three measures results were not consistent and IP saliency not foremost. For movement measures, $C o$ signal $(F=6.46 ; p<.05), I P$ (F= $4.24 ; p<.05)$, and an all factor interaction ( $p<.05$ ) were found. Tukey HSD tests on positions across orientations were not significant, but IP's differed across gignals. Apparently, the interaction was introduced by WN use, although it was limited to sagittal and $90 \mathrm{R}$ orientations and at the $+0.5 \mathrm{~m} \mathrm{IP}$. ( $\mathrm{F}=10.89$; $\mathrm{p}<.05)$. The "errors" ANOVA corroborated Co significance $(F=18.2 ; p<.05)$, but the only interaction was IP $x$ orientation $(F=26.6, p<.01)$. Post hoc examinations of the joint effects of Co's and IP'g demonstrated that WN terminal placements were always "beyond" the std, and except for -1.0m IP, always in front of the std for the tone. With ratio scores, IP was again significanct $(F=4.5 ; p<.05)$ along with a Co $x$ IP $x$ orientation interaction $(F=15.3 ; p<.01)$. Fig. 2 shows the interaction and indicates greater movements were observed for tones initially aft of than fore of the std, while the opposite was noted for WN stimuli. Finally, when ratio means were collapsed across orientations, the IP effect remained.

\section{DISCUSSION}

Apparently, within this paradigm, binaural cues may not greatly affect accurate acoustic depth judgements. In study $I$ normal and non-normal hearers were not significantly different with presumably reduced binaural cues (sagittal plane entry), and even binaurally -impaired hearers were not greatly debilitated. At worst, the latter Ss: absolute "errors" were greater, and they had a different pattern of depth accuracy (ratio data Fig. I). In Study II, normal hearers were no better judging depth with more maximal binaural cues available ( $90 \mathrm{~L}$ \& $\mathrm{R}$ entries). In fact, overall it seems that depth is more easily resolved along the sagittal plane (Fig 2 , open and filled circles) where binaural cues are presumably minimized.

Previous evidence using this paradigm, until study II here, had consistently suggested that acoustic depth judgement accuracy was accomplished by a comparison of the intensities, as relative cues, of the tonal signal. The static std was always an unchanging anchor point against which to make the comparison, and frequency although a non significant factor, perceptively helped keep the different intensity signal separable. However, broadband signal introduction apparently makes the judgement process more difficult because frequencies become highlighted and it is more difficult to attend primarily to relative intensities. Usual tendencies/ strategies to over- and underestimate distances from positions respectively in front of, and aft of an anchoring point no longer work. In short, more factors ( here, wN and tonal signals; IP's; and movement direction) enter the judgement process. For example, WN may begin to be a masker as signals approximate. Perhaps too, the shorter total observation distances $(2 \mathrm{~m})$ used here also helped negate the intensity cue differences. Such speculations seem to support the Mershon et al's (1989) model of depth resolution as fine interplay of identifiable relative and absolute cue values. However, given the interaction of factors here, and the possibly masking role of wN, it is not as easy as the model implies to indicate which cues carry which information type. 
Figure 1

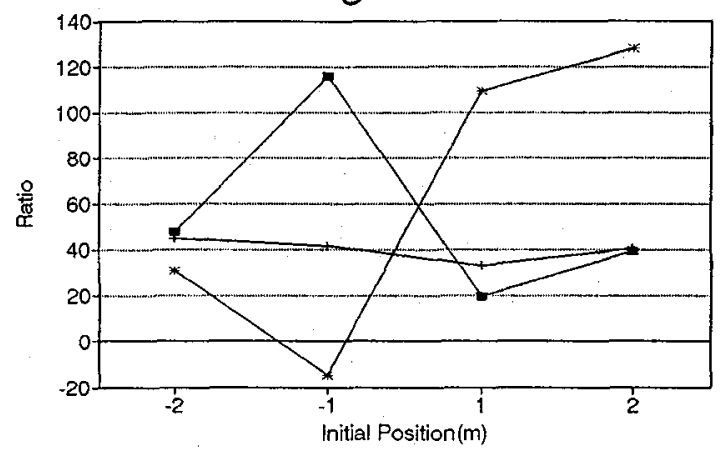

$\rightarrow-$ Control $\rightarrow$ Monaural Impaired $\approx$ Binaural Impaired

Fig. 1: Mean Ratio Scores for Initial positions (O degree position removed) by Hearing Condition collapsed across comparison frequencies

Figure 2

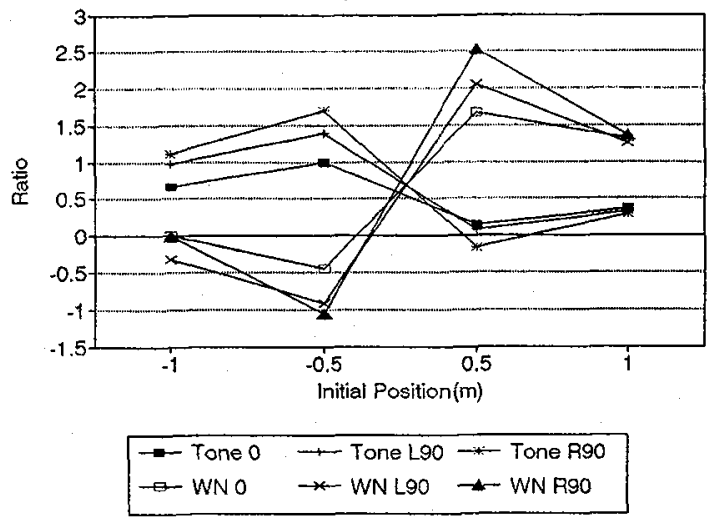

Fig 2: Mean Ratio scores for Initial positions (0 degree position removed) by Comparison Signal (Tone; WN) and Orientation

\section{REFERENCES}

/1/Starch,D.\& Crawford,A.I. Psych.Rev. (1909), 16, 427-430

/2/Gamble, R.A. Psych. Rev. (1909), 16, 416-426

/3/Coleman,P.D. J. Acoust. Soc. Am. (1968), 44, 631-632

/4/Blauert, J. Spatial Hearing, (1983), Cambridge, MIT Press

/5/Simpson, w.E. \& Stanton, L.D. Am. J. Psychol. (1973), 86, 151-159

/6/Gardner, M.B. J. Acoust. Soc. Am. (1969), 45, 47-53

/7/Mershon,D.H.,Desaulnier,D.H.\& Amerson, T.L. J. Aud. Res. (1980), 20, $129-136$

/8/Waugh,W.,Strybel, T.z.\& Perrott,D.R. J. Aud. Res. (1981), 24, 124-132

19/Gatehouse, R.W.\& Pattee,C.L. Can. Acoust. (1985), 13, 3-14

/10/Mershon,D.H.\& King,E. Percept. \& Psychophys. (1975), 6, 409-415

/11/Mershon,D.H.\& Bowers, J.N. Percept. (1979), 8, 311-322

/12/Mershon,D.H., Ballenger, W.I., Little, A.D., McMurty, P.L.\& Buchanan,J.I. (1989),

$18,403-416$ 